\title{
Deep Learning Verifikasi Kemiripan Wajah Dengan Arsitektur Jaringan Siamese
}

\author{
Kartarina $^{1}$, Hairul Imam ${ }^{2}$ \\ ${ }^{1}$ Universitas Bumigora, kartarina@universitasbumigora.ac.id \\ ${ }^{2}$ Universitas Bumigora, ki65559@gmail.com
}

\begin{abstract}
Abstrak
Verifikasi wajah adalah masalah yang cukup populer dalam bidang computer vision. Banyak pendekatan yang telah dilakukan untuk menyelesaikan masalah tersebut baik menggunakan model matematika murni dengan mempelajari pola geometri pada wajah secara manual maupun cara otomatis menggunakan pendekatan pembelajaran mesin. Penelitian ini mencoba memecahkan masalah tersebut dengan pendekatan deep learning, dimana model dilatih menggunakan triplet loss yang didefinisikan pada paper FaceNet. Rancangan model yang digunakan adalah Siamese dengan menerapkan ResNet-50 yang telah dimodifikasi untuk mempelajari fitur yang ada pada gambar sehingga mampu mereduksi dimensi gambar yang tinggi menjadi vektor baris yang rendah disebut sebagai embedding. Setelah model berhasil mempelajari embedding yang baik pada gambar maka masalah verifikasi wajah bisa diselesaikan dengan membandingkan jarak embedding antar gambar dimana jarak yang dekat dapat diartikan sebagai wajah yang mirip (genuine) dan jarak yang jauh dapat diartikan sebagai wajah yang berbeda (impostor). Pada penelitian ini, model berhasil dilatih pada Dataset VGG Face v2 (Visual Geometry Group) dengan nilai akurasi $92 \%$ pada Dataset LFW (Labeled Faces in the Wild) sebagai data testing dan mendapatkan nilai AUC (Area Under the Curve) 97\%. Nilai AUC yang tinggi dapat diartikan bahwa model dapat memverifikasi dengan baik gambar wajah orang yang sama sebagai genuine dan gambar wajah orang yang berbeda sebagai impostor.
\end{abstract}

Kata Kunci: Siamese, Triplet Loss, Verifikasi Wajah, Face Embedding, Dimensionality Reduction.

\begin{abstract}
Face verification is a quiet popular problem in computer vision. Various approach has been applied to solve this problem from using pure mathematical model by manually defining Face geometric pattern into automatic way by using machine learning. This research try to solve this problem using deep learning approach. The model will be trained using Triplet Loss as defined in the Face Net paper. The model architecture that will be used is Siamese by applying modified ResNet-50 as the body of the Network, the Network will be trained as how to reduce high dimension image into a low dimension row vector, reduced image dimension into a low row feature vector also called embedding. If model successfully trained to produce a good embedding quality of an image then Face verification problem can be seen as Pythagorean problem where the distance of two pair of images can be calculated using euclidean distance those the distance can be seen as the similarity value which by applying some threshold value we can determine if those pair of images is genuine (similar) or not (impostor). This Research, model successfully trained on VGG Face v2 (Visual Geometry Group) Dataset by getting 92\% accuracy on LFW (Labelled Face in the Wild) as testing Dataset. Also the AUC (Area Under The Curve) score is reacing 97\%, high AUC score can be interpreted that the model is successfully verify similar person as genuine and different person as impostor.
\end{abstract}

Keywords: Siamese, Triplet Loss, Face Verification, Face Embedding, Dimensionality Reduction.

\section{Pendahuluan}

Masalah verifikasi kemiripan wajah adalah masalah pencocokkan antar dua gambar wajah untuk memperoleh suatu kesimpulan apakah kedua gambar wajah merupakan orang yang sama (genuine) atau berbeda (impostor), kesimpulan tersebut diambil dari hasil membandingkan ciri-ciri wajah yang ada pada dua gambar individu tersebut. Kebergantungan sebuah kesimpulan verifikasi berdasarkan perbandingan ciri wajah dari dua individu menyebabkantantangan utama dalam masalah ini adalah seberapa handal sebuah metode atau algoritma dalam mengenali ciri-ciri (feature) pada gambar wajah. Metode pembelajaran pola geometry 
wajah secara manual menggunakan pendekatan matematis, endekatan yang lain yaitu menggunakan pendekatan deep learning. Dengan metode deep learning pembelajran fitur pada wajah bisa dilakukan secara otomatis dengan mempelajari pola pada sekumpulan data dalam jumlah besar tanpa memerlukan pengetahuan tambahan dari lingkup luar (prior knowledge), cukup hanya dengan analisa otomatis pada data yang diberikan (feature extraction).

Berdasarkan hal tersebut penelitian ini menggunakan pendekatan deep learning. Dimana arsitektur jaringan yang digunakan adalah Siamese dengan badan jaringan menggunakan ResNet-50 yang telah dimodifikasi, lalu jaringan akan dilatih dengan fungsi triplet loss. Fungsi triplet loss digunakan dengan objektif mereduksi dimensi gambar wajah yang tinggi menjadi vektor baris dengan dimensi lebih rendah yang dapat merepresentasikan fitur gambar wajah (feature vector / embedding).

Setelah model berhasil dilatih dengan optimal, maka model bisa digunakan untuk mendapatkan representasi feature vector dalam dimensi lebih rendah dari gambar wajah yang dapat langsung digunakan untuk menyelesaikan masalah verifikasi wajah dengan membandingkan jarak feature vector antar gambar. Adapun cara melatih jaringan dengan triplet loss agar mendapatkan hasil embedding yang optimal akan dijelaskan pada bagian III.

\section{Topik Berkaitan}

Ada beberapa penelitian dalam menyelesaikan masalah serupa yang telah dilakukan, seperti yang dilakukan oleh Tri Mulyono dkk[1] dimana pada penelitian tersebut pendekatan yang digunakan adalah menggabungkan metode eigenFace dengan JST (Jaringan Syarat Tiruan). Dimana fitur dari citra wajah diekstrak terlebih dahulu menggunakan metode PCA (Principal Component Analysis) lalu hasil fitur yang telah diekstrak tersebut akan digunakan sebagai masukkan (input) ke JST. Dalam kasus seperti ini jaringan JST hanya dilatih untuk mengenali fitur yang didapatkan melalui ekstraksi fitur manual pada proses PCA. JST tidak dilatih untuk mengenali dan mengambil informasi fitur secara otomatis, sehingga tingkat kebaikan PCA dalam mengekstrak dan mengenali fitur wajah menjadi penentu keberhasilan utama dari metode ini. Pada penelitian tersebut JST berhasil dilatih pada 120 Dataset dengan 10 individu dan dapat mengenali rata-rata sebanyak $84,6 \%$ dari data evaluasi.

Pendekatan serupa juga telah dilakukan oleh Dimas Achmad Akbar Kusuma [2] dimana dalam mengekstrak fitur wajah metode yang digunakan adalah Discrete Cosine Transform lalu hasil dari proses ini akan menjadi masukkan ke JST. JST akan dilatih berdasarkan fitur yang didapat pada proses Discrete Cosine Transform.Pada penelitian tersebut jumlah gambar wajah yang digunakan adalah 100 dimana terdapat 10 individu dengan 10 pose yang berbeda-beda dan berhasil mendapat akurasi sebanyak $90 \%$ hingga $100 \%$ pada proses evaluasi dengan individu yang sama pada saat proses latihan.

Melakukan ekstraksi fitur secara manual seperti dua metode diatas masuk keruang lingkup classical learning dimana fitur diekstrak terlebih dahulu menggunakan algoritma tertentu lalu hasil fitur yang telah diekstrak akan menjadi masukkan (input) ke algoritma yang menyelesaikan masalah terkait. Pendekatan yang demikian memiliki hasil yang baik dalam ruang lingkup data yang relatif sedikit, belum diuji apakah metode yang sama dapat mengekstrak fitur pada gambar wajah yang lebih beragam dan dengan jumlah Dataset yang lebih besar lagi.

\section{Metodologi}

Pada penelitian ini fungsi yang akan digunakan untuk melatih jaringan dalam mempelajari embedding yang baik adalah fungsi triplet loss seperti yang didefinisikan dalam paper FaceNet oleh Florian Schroff dkk[3]. Dimana komponen utama dari triplet loss adalah adanya 3 pasangan gambar yang disebut pasangan triplet yang terdiri dari gambar anchor yaitu gambar acuan, gambar positive yaitu gambar individu yang sama dengan gambar anchor dan gambar negative yaitu gambar individu yang berbeda dari gambar anchor. 


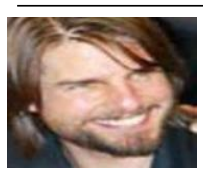

Anchor

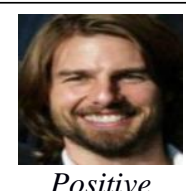

Positive

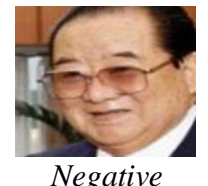

Negative
Gambar disebut pasangan triplet yang valid ketika sudah memenuhi kriteria yaitu gambar anchor dan positive terdiri dari individu yang sama dan gambar negative merupakan individu yang berbeda. Adapun objektif dari fungsi ini adalah agar jarak antar embedding anchor dengan positive lebih kecil dari jarak embedding antar anchor dengan negative, seperti terlihat dalam persamaan (1) dibawah.

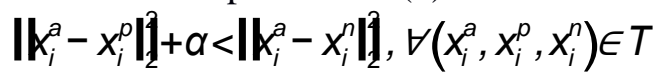

Dimana nilai ${ }^{\alpha}$ adalah sebuah margin yang memastikan adanya perbedaan nilai antar jarak gambar positive dan negative dengan anchor. Sehingga fungsi triplet loss yang harus diminimalkan adalah seperti persamaan (2) berikut ini.

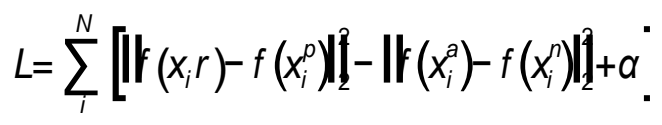

Secara intuisi persamaan diatas bisa dibaca bahwa nilai jarak antar gambar positive harus seminimal mungkin hingga lebih kecil dari jarak gambar negative, nilai ${ }^{\alpha}$ pada persamaan (2) diatas untuk memastikan bahwa jarak gambar positive harus lebih kecil dari gambar negative namun tidak melebihi nilai margin sehingga nilai loss tetap berada pada nilai positive. Ilustrasi objektif pembelajaran triplet loss bisa dilihat pada gambar $2^{1}$ dibawah.

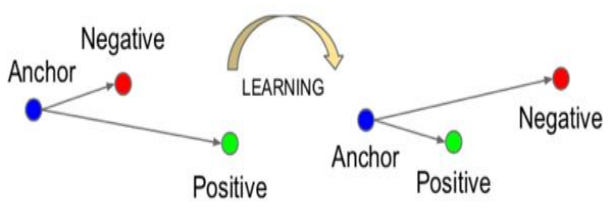

Gambar 2. Ilustrasi Objektif Triplet Loss.

1

Sumber gambar paper FaceNet, referensi nomor 3 .
Model harus dilatih sehingga jarak antar gambar positive lebih kecil dari jarak gambar negative. Melihat persamaan (2) diatas, tidak semua pasangan triplet bisa digunakan untuk melatih jaringan. Pada bagian dibawah ini akan dijelaskan beberapa pilihan triplet yang bisa digunakan untuk melatih jaringan.

\section{A. Pemilihan Triplet}

Agar dapat melatih jaringan dengan optimal dibutuhkan pasangan triplet yang baik, adapun beberapa jenis triplet seperti berikut:

\section{1) Easy Triplet}

Easy triplet adalah jenis triplet yang sudah memenuhi fungsi kendala pada persamaan (1). Jenis triplet seperti ini tidak perlu digunakan untuk melatih jaringan karena memiliki nilai loss 0 dan dapat menyebabkan convergent yang lebih lama. Secara matematis jenis triplet seperti ini bisa diekspresikan seperti persamaan (3) dibawah.

$$
d\left(f\left(x^{a}\right), f\left(x^{p}\right)\right)+\alpha<d\left(f\left(x^{a}\right), f\left(x^{n}\right)^{\prime}\right.
$$

Dimana $d$ adalah fungsi jarak, sehingga persamaan diatas bisa diartikan bahwa jarak gambar anchor dan positive ditambah margin lebih kecil dari jarak gambar anchor dengan negative.

\section{2) Hard Triplet}

Hard tripletadalah pasangan triplet yang dimana jarak antar gambar negativedengan anchor lebih kecil dari jarak gambar positivedengan anchor. Jenis triplet ini bisa diekspresika seperti persamaan (4) .

$$
d\left(f\left(x^{a}\right), f\left(x^{n}\right)\right)<d\left(f\left(x^{a}\right), f\left(x^{p}\right)\right)
$$

\section{3) Semi-hard Triplet}

Semi-hard triplet adalah jenis triplet yang jarak gambar negative dengan anchor lebih kecil dari jarak antar gambar positive dengan anchor ditambah margin namun tidak lebih kecil dari jarak gambar anchor dan positive tanpa margin, sehingga bisa diartikan selisih jarak gambar negative dengan positive pada triplet ini tidak melebihi nilai margin. Jenis triplet ini 
bisa diekspresikan seperti persamaan (5) dibawah.
Adapun blok layer ResNet-50 yang utuh dapat dilihat seperti gambar 4 dibawah.

$$
d\left(f\left(x^{a}\right), f\left(x^{p}\right)\right)<d\left(f\left(x^{a}\right), f\left(x^{n}\right)\right)<d\left(f\left(x^{a}\right), f\left(x^{p}\right)\right)+\alpha
$$

(5)

Setelah mengetahui jenis-jenis triplet diatas, adapun yang bisa digunakan untuk melatih jaringan adalah jenis hard triplet dan semi-hard triplet. Pada penelitian ini jenis triplet yang dipilih adalah semi-hard triplet.

B. Arsitektur Jaringan

Secara garis besar arsitektur jaringan yang digunakan terlihat seperti gambar 3 dibawah.

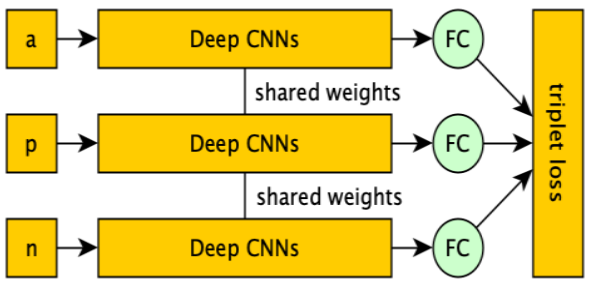

Gambar 3. Gambaran Besar Struktur Jaringan.

Setiap pasangan gambar triplet akan melewati jaringan dengan parameter yang sama (shared weights) fitur dari gambar akan dipelajari secara otomatis pada lapisan Deep CNNs lalu hasil fitur yang dipelajari akan dimasukkan ke lapisan Fully Connected Layer(FC). Lapisan FC akan dilatih agar dapat menghasilkan featurevector (embedding) yang baik menggunakan fungsi triplet loss.

1) Siamese

Ide utama dari Siamese adalah melewatkan sebuah input melalui dua (twine) atau tiga (triplet) arsitektur jaringan yang identik yang berbagi nilai parameter yang sama sehingga pada saat trainingmasukkan yang dilewatkan pada arsitektur jaringan tersebut diproses dengan nilai parameter yang sama pada saat bersamaan. Pada gambar 3, arsitektur jaringan yang identik terdapat berjumlah tiga dengan berbagi nilai parameter yang sama, adapun arsitektur Deep CNNs pada arsitektur tersebut menggunakan blok layer ResNet-50 yang telah dimodifikasi seperti dijelaskan pada bagian berikut.

2) Modifikasi ResNet-50

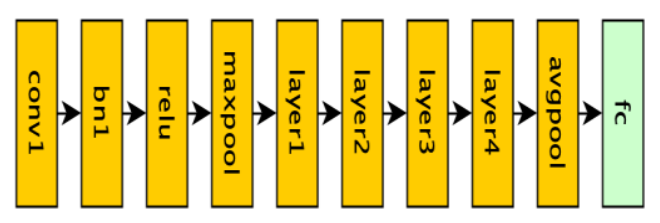

Gambar 4. Blok Layer ResNet-50 Yang Utuh.

Blok layer ResNet-50 yang utuh tanpa modifikasi terdiri dari layer conv1, bn1, relu, maxpool, layer1, layer2, layer3, layer4, avgpool dan layer fc. Modifikasi layer ResNet-50 yang dilakukan pada penelitian ini berdasarkan penelitian yang dilakukan oleh Hermans dkk [4] dan Rajeev Ranjan dkk [5].

L ayer ResNet-50 yang dilakukan yaitu pembuangan layer avgpool dan penambahan operasi L2-Normalize dan operasi perkalian skala alpha pada layer FC. Adapun operasi L2-Normalize dan perkalian skala alpha yang dilakukan pada layer fc bisa dilihat pada persamaan (6) dan persamaan (7) berikut

$$
\begin{aligned}
& y=\frac{x}{|| x||} \\
& z=y \cdot \alpha
\end{aligned}
$$

Pada proses L2-Normalize persamaan (6) setiap titik nilai pada input akan dinormalkan dengan norm L2 dari vektor input, lalu hasil dari proses ini akan dikalikan dengan skala alpha persamaan (7). Nilai skala alpha dapat dilatih selama proses training seperti parameter yang lain, namun pada paper [5] Rajeev Ranjan menyebutkan bahwa pemberian nilai tetap pada variabel alphadengan nilai yang rendahmemberikan performa yang lebih baik, pada penelitian ini nilai alpha yang digunakan adalah 10.

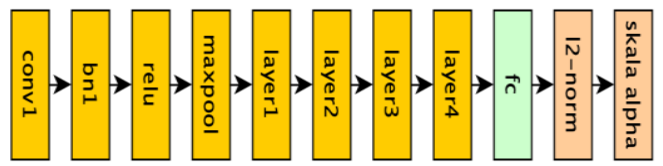




\section{Gambar 5. Blok Layer ResNet-50 Setelah} Modifikasi.

Modifikasi layer ResNet-50 dengan pembuangan layer avgpool dan penambahan operasi 12-norm dan skala alpha pada layer FC. Setiap masukkan gambar akan melalui setiap blok layer ResNet seperti tabel 1 diatas. Layer conv1 adalah layer pertama pada layer ResNet yang akan dilalui input, layer conv1 menerima masukkan gambar berupa 3 kanal warna dengan ukuran $224 \times 224$.

Angka 1 pada dimensi tensor tersebut menunjukkan jumlah gambar yang dimasukkan dalam satu waktu (batch size). Rincian masukkan dan keluaran setiap blok layer ResNet-50 disajikan pada tabel 1 berikut ini.

TABEL I. RINCIAN MASUKKAN DAN KELUARAN BLOK RESNET

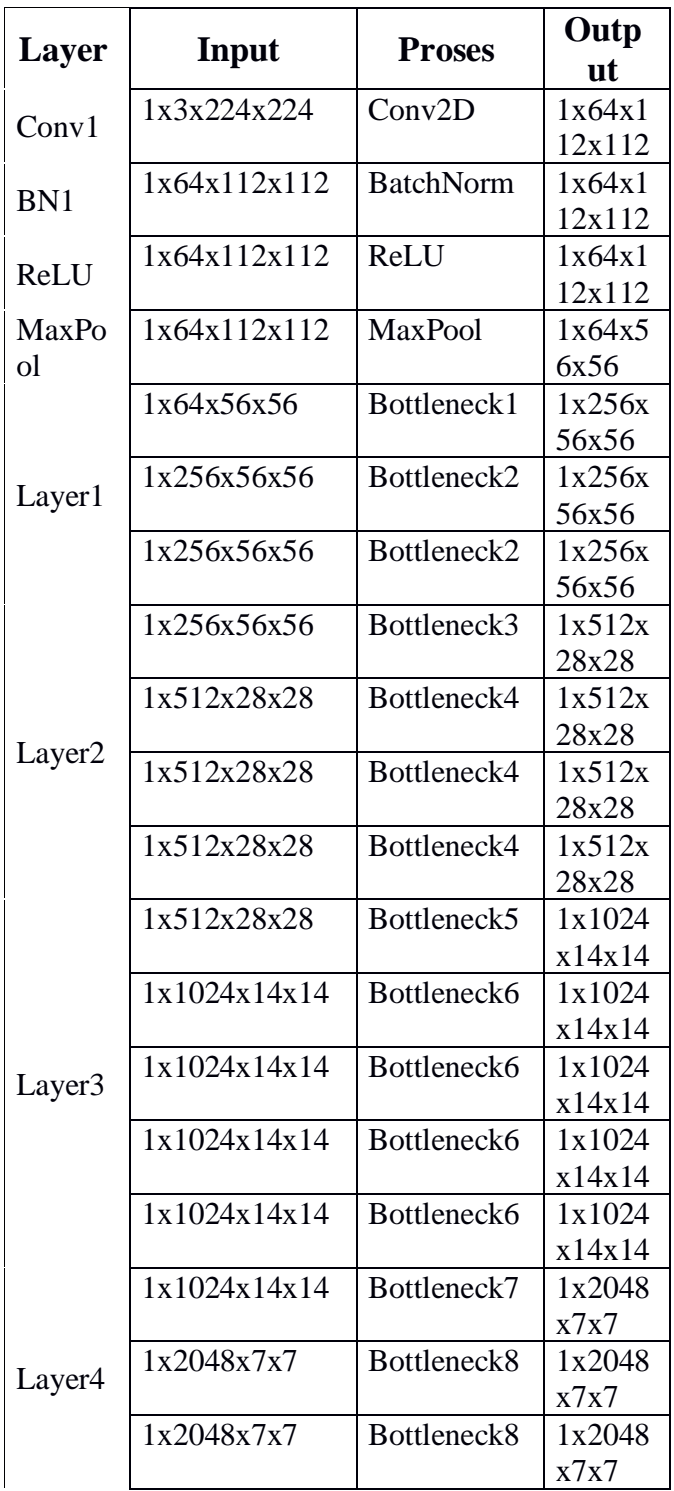

\begin{tabular}{|l|l|l|l|}
\cline { 2 - 4 } & FC $1 \times 100,352$ & Linear & $1 \times 128$ \\
\hline
\end{tabular}

Jika pada saat training menggunakan 64 batch size maka dimensi tensor menjadi $64 \times 3 \times 224 \times 224$ begitu juga dengan dimensi tensor pada layer yang lain akan berubah.

Lapisan conv1 sampai lapisan Layer 4 adalah yang dimaksud blok Deep CNNs pada gambar 3, hasil dari blok Deep CNNs pada layer ResNet adalah tensor dengan dimensi $1 \times 2048 \times 7 \times 7$ untuk setiap masukkan gambar.

Fitur yang berhasil dipelajari pada blok Deep CNNs lalu dimasukkan ke lapisan FC sebagai fitur yang akan dipelajari untuk mendapatkan embedding yang baik, fitur yang masuk ke layer FC berjumlah 100,352 didapat dari hasil proses flatten (perataan) fitur pada layer Deep CNNs jika dimensi $(1 \times 2048 \times 7 \times 7)$ dikalikan akan menghasilkan 100,352. Keluaran dari proses layer $\mathrm{FC}$ adalah vektor baris dengan dimensi $1 \times 128$ yang akan menjadi dimensi dari embedding yang dipelajari. Sehingga semua gambar dengan dimensi tinggi cukup bisa diwakili hanya dengan representasi vektor baris dengan dimensi $1 \times 128$.

\section{Proses Training dan Testing}

Secara garis besar proses melatih dan menguji model Pada tahap pertama model akan dibangun, jika sudah ada weight yang tersimpan dari proses training sebelumnya maka weight akan dimuat ke model.

Proses training dan testing akan dilakukan sebanyak epoch yang diinginkan atau sehingga model dianggap belajar dengan baik dengan akurasi testing yang memuaskan. Dalam setiap iterasi epoch akan dilakukan pembuatan pasangan triplet secara acak untuk data training dan data testing,

Data training diproses untuk training dan datatesting dimasukkan ke proses testing. Proses ini berulang hingga objektif tercapai seperti gambar 6 berikut: 


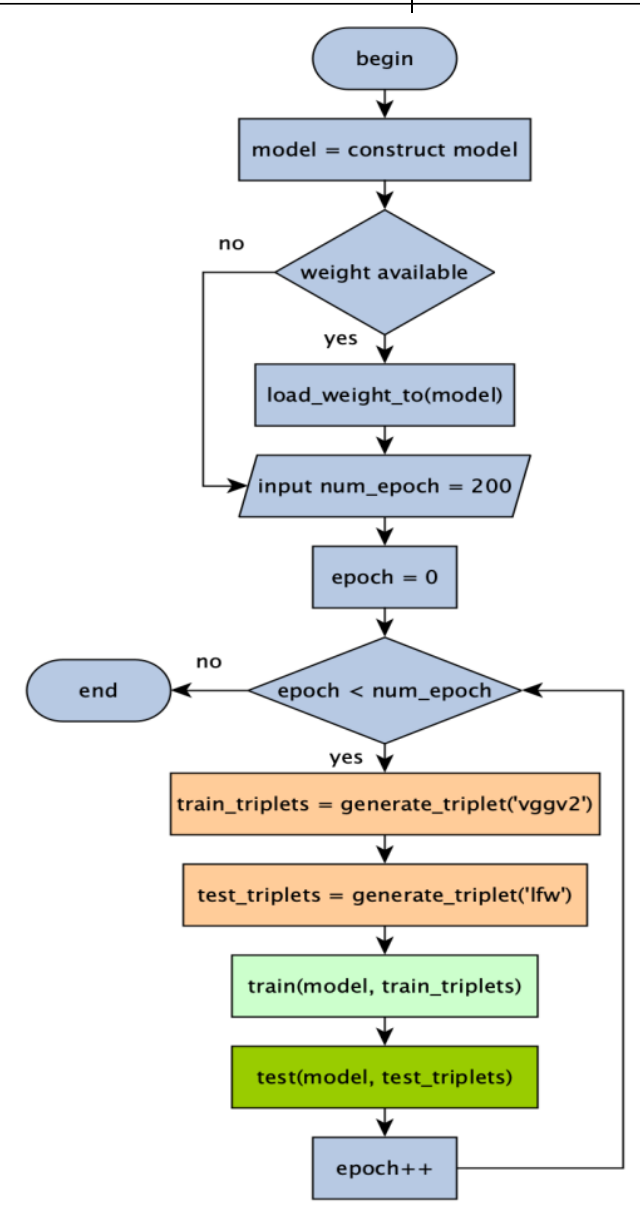

Gambar 6. Gambaran Besar Proses Training Dan Testing.

\section{1) Dataset}

Dataset yang digunakan dalam penelitian ini ada dua yaitu Dataset VGG (Visual Geometry Group) Face v2 sebagai Dataset untuk latihan dan Dataset Labeled Face in the Wild (LFW) sebagai data uji coba. Kedua Dataset ini merupakan Dataset yang sangat terkenal dalam melakukan penelitian Face Recognition atau computer vision dengan deep learning secara umum karena keberagaman data dan jumlah data dimiliki.

Dataset VGG Face v2 memiliki 9000 jenis identitas dengan variasi etnis, aksen, profesi dan umur yang berbeda dan memiliki 3,3 juta gambar. Dataset ini didistribusi secara bebas dengan lisensi Creative Common Attribution-ShareAlike 4.0.

Dataset LFW disediakan oleh University of Massachusetts. Dataset ini merupakan acuan pengujian seluruh peneliti computer vision dalam bidang pengenalan wajah saat ini. Dataset ini berisi 13,233 gambar dengan 5749 jenis individu dimana 1680 diantaranya memiliki lebih dari satu gambar wajah dan 4096 sisanya masing-masing hanya memiliki 1 gambar wajah.

2) Generate Triplet

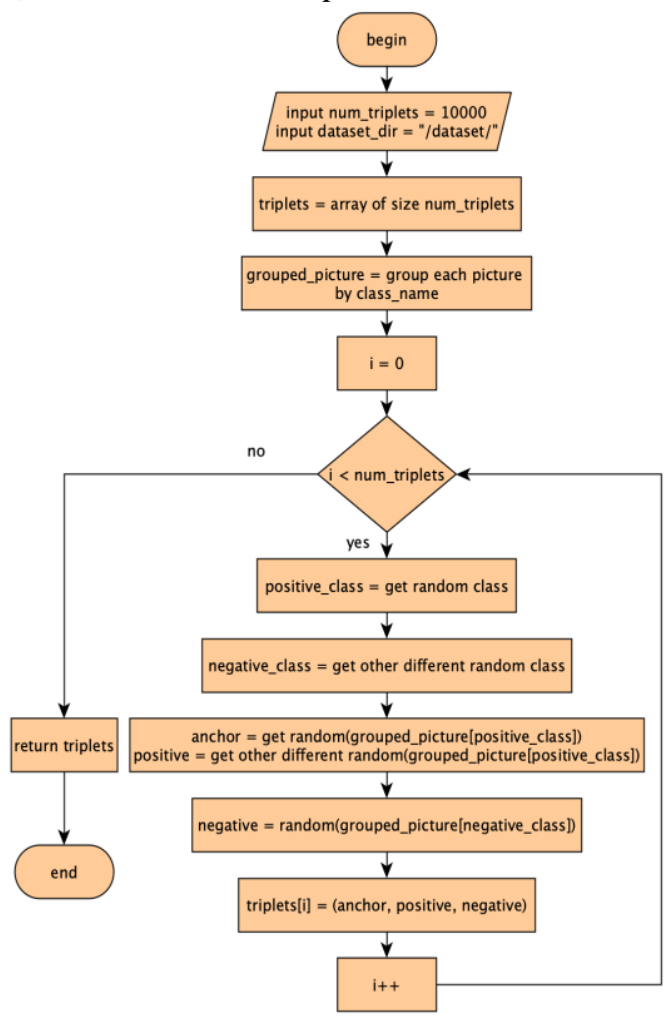

Gambar 7. Alur Pembuatan Pasangan Triplet Acak.

Pertama tentukan jumlah pasangan triplet yang valid yang diinginkan. Lalu lakukan perulangan, pada setiap perulangan ambil class (individu) secara acak lalu ambil dua gambar dari individu tersebut sebagai gambar anchor dan positive, lalu ambil satu gambar dari individu yang berbeda secara acak sebagai gambar negative.

\section{3) Proses Training}

Jumlah iterasi pada proses training adalah jumlah bagian pasangan triplets acak setelah dibagi dengan batch size. Bagian penting pada proses training adalah pada proses pemilihan triplet yang baik untuk melatih model. Pada flowchart gambar 8 diatas, proses pemilihan triplet dilakukan pada blok proses ke 4 dalam lingkup perulangan.

Pada gambar 8 menjelaskan bahwa hasil perhitungan jarak positive dan negative dari embedding triplet secara acak akan dilakukan proses pengurangan, pada tahap 
ini jika nilai neg_distance lebih besar dari nilai pos_distance+margin maka tidak ada pasangan semi_hard_triplets yang didapat karena tidak ada yang memenuhi kondisi

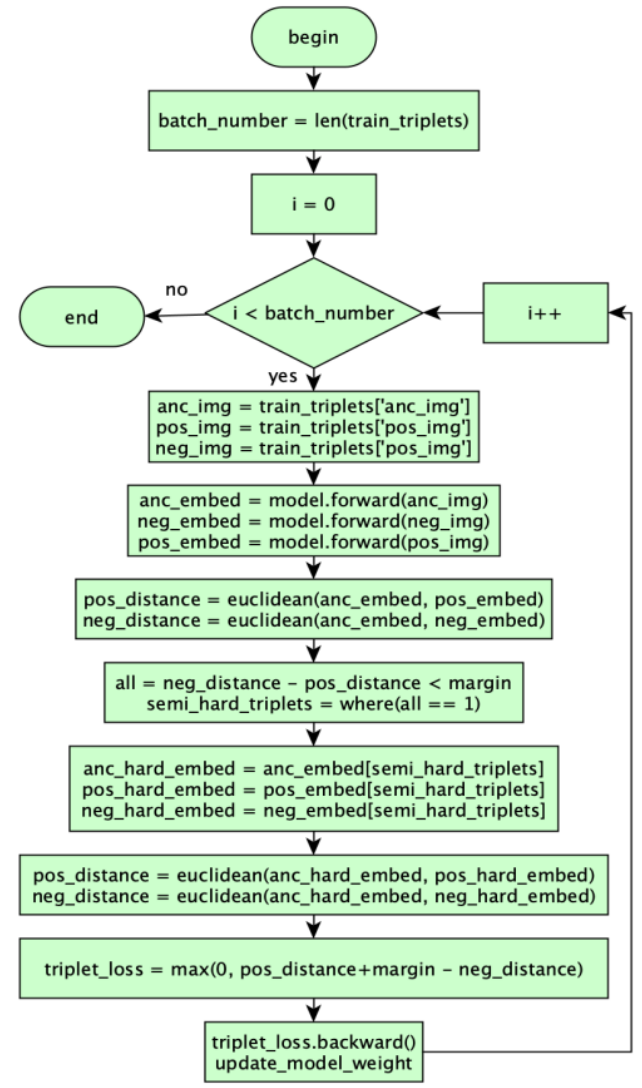

Gambar 8. Alur Kerja Proses Training.

Jika nilai neg_distance lebih besar namun selisihnya tidak melebihi nilai margin maka pasangan semi_hard_triplets bisa di dapat. $\mathrm{P}$

Pasangan semi_hard_triplets pada proses adalah proses yang akan digunakan untuk melatih model pada proses perhitungan triplet_loss sehingga weight model bisa diperbarui berdasarkan nilai gradient yang didapat dari sebuah operasi backpropagation milailosssemi_hard_triplets.

\section{4) Proses Testing}

Nilai akurasi pada proses testing didapat berdasar rata-rata akurasi pada setiap iterasi. Pada proses testing untuk mendapatkan nilai akurasi model akan dihitung jumlah verifikasi truepositive dan truenegative berdasarkan rentang nilai Threshold tertentu. Rentang nilai Threshold yang digunakan yaitu nilai 0,5 sampai 5,0 dengan selisih masing-masing 0,1 .

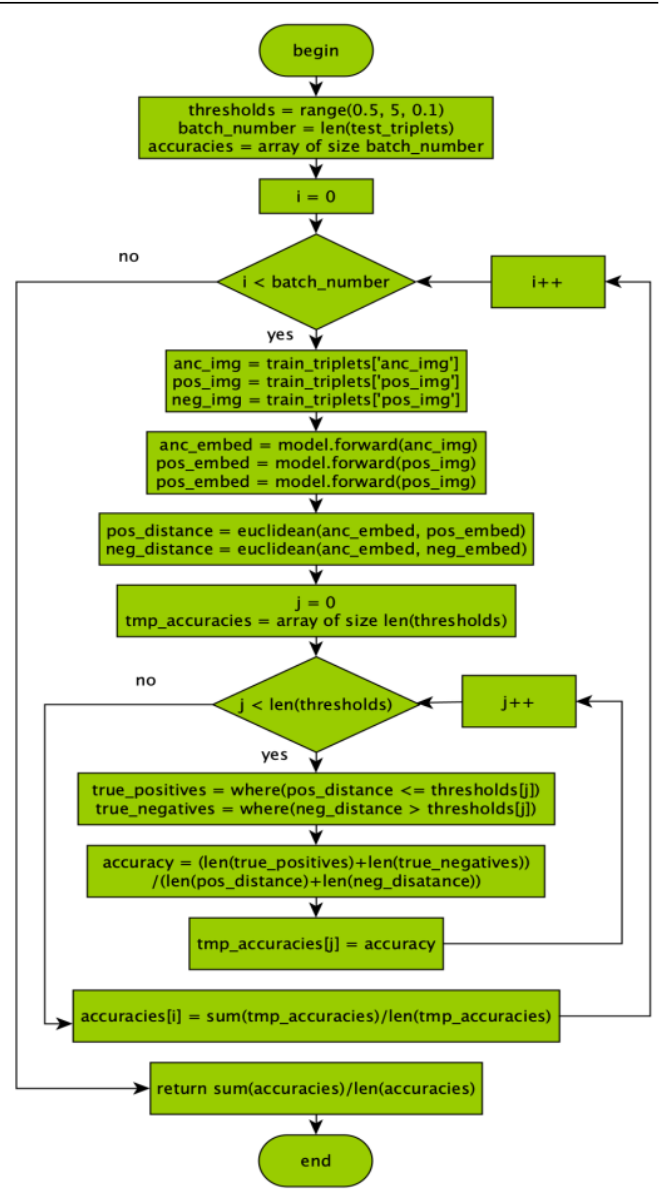

Gambar 9. Alur Kerja Proses Testing.

\section{HASIL DAN PEMBAHASAN}

Untuk melakukan proses training dan testing pada penelitian ini digunakan layanan GCP (Google Cloud Platform) dengan konfigurasi hardware dan software sebagai berikut:

\begin{tabular}{|c|c|}
\hline \multirow{5}{*}{$H A R D W A R E$} & $\begin{array}{l}4 \times 12 G B \text { NVIDIA Tesla } \\
\text { K80 GPU }\end{array}$ \\
\hline & $\begin{array}{l}8 \text { Core } v C P U \text { Intel } \\
\text { Broadwell }\end{array}$ \\
\hline & $52 G B R A M$ \\
\hline & 256GB Boot Disk \\
\hline & 200GB Dataset Disk \\
\hline \multirow{4}{*}{ SOFTWARE } & $\begin{array}{l}\text { Debian 4.9.130-2(2018- } \\
\text { 10-27) x86_64 GNU/Linux }\end{array}$ \\
\hline & Python v3.7.1 \\
\hline & Pytorch v1.0 \\
\hline & CUDA v10.0 \\
\hline
\end{tabular}

Adapun proses training dan testing dibagi menjadi dua tahap, pertama training dan testing pada layer FC kedua training dan testing pada layer ekstraksi fitur (Deep CNNs). 
1) Training dan Testing Layer FC

Pada proses ini masukkan dari layer FC adalah hasil proses layer ekstraksi fitur (Deep CNNs) dengan weight dari pretrained ResNet-50. Layer ekstraksi fitur akan dilatih kembali untuk mempelajari ciri wajah pada Dataset training. Pada proses melatih layer FC model dapat dilatih hingga mendapat loss 0.008 pada data train dan 0.002 pada data testing. Hasil latihan pada proses ini terlihat pada gambar 10 dan gambar 11 grafik berikut ini:

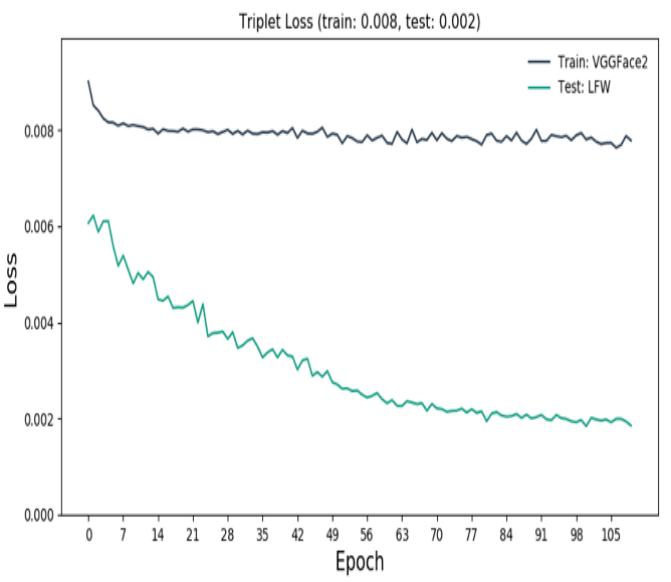

Gambar 10. Hasil Loss Setiap Epoch Layer FC

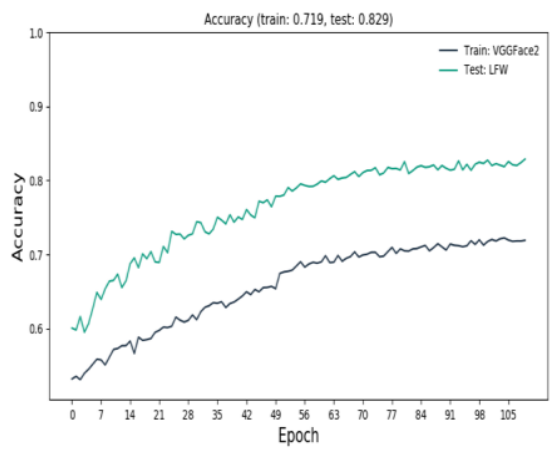

Gambar 11. Hasil Akurasi Setiap Epoch Layer FC.

Pada proses melatih layer FC model dapat dilatih hingga mendapat akurasi $71 \%$ pada data train dan $82 \%$ pada data testing.

2) Training dan Testing Layer Ekstraksi Fitur

Pada proses ini layer ekstraksi fitur (Deep CNNs) akan dilatih kembali agar dapat mempelajari ciri wajah pada data training. Adapun hasil latih dan uji pada proses ini bisa dilihat pada gambar 12 .

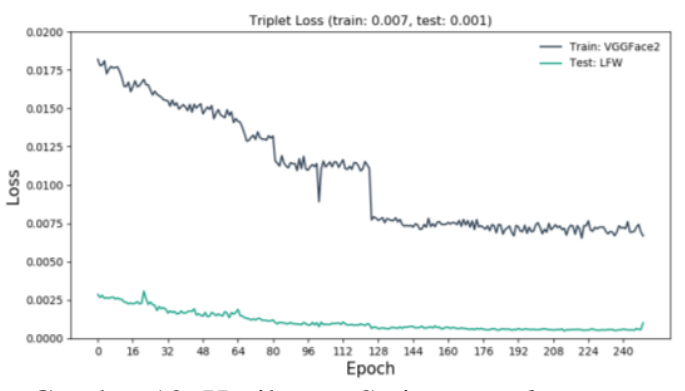

Gambar 12. Hasil Loss Setiap Epoch Layer Ekstraksi Fitur.

Pada proses melatih layer ekstraksi fitur model dapat dilatih hingga mendapat nilai loss 0.007 pada data training dan nilai 0.001 pada data testing.

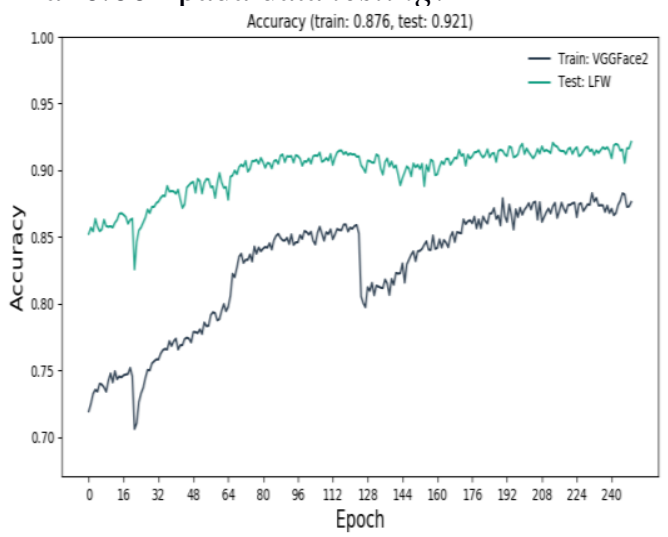

Gambar 13. Hasil Akurasi Setiap Epoch Layer Ekstraksi Fitur.

Pada proses melatih layer ekstraksi fitur model dapat dilatih hingga mendapat nilai akurasi $87 \%$ pada data training dan nilai $92 \%$ pada data testing.Bisa dilihat pada gambar 13 , model telah berhasil dilatih hingga mendapat nilai akurasi $87 \%$ pada training dan $92 \%$ pada testing.

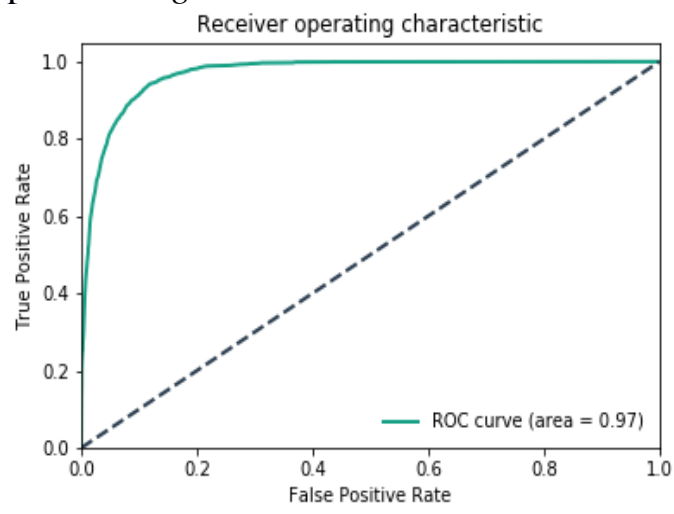

Gambar 14. Grafik ROC Dan Nilai AUC.

Nilai akurasi testing yang lebih tinggi dari nilai akurasi training menunjukkan bahwa model telah belajar dengan baik dan tidak terjebak overfit 
hingga mampu melakukan generalisir pada data baru. Grafik ROC (Receiver Operating Characteristic) pada proses training dan testing terakhir bisa dilihat pada gambar 14.

Pada proses training terakhir model berhasil mendapat nilai AUC (Area Under the Curve) sebanyak 97\%.Nilai AUC mencapai $97 \%$ bisa diinterpretasikan bahwa model dapat memverifikasi dengan benar gambar wajah orang yang sama dan orang yang berbeda dengan persentase $97 \%$ selama proses pengujian.

\section{3) Percobaan Verifikasi Wajah}

Setelah model berhasil dilatih hingga mendapat nilai akurasi $92 \%$ pada data testing, pada bagian ini akan dilakukan percobaan verifikasi wajah 30 pasangan individu secara acak dengan nilai threshold yang berbeda-beda seperti dijelaskan pada sub sub bab Proses Testing. Lalu akan dihitung jumlah true positive dan true negative setiap nilai threshold.

TABEL 2. RINCIAN JUMLAH BENAR SETIAP NILAI THRESHOLD

\begin{tabular}{|c|c|}
\hline Nilai Threshold & Jumlah Benar \\
\hline 0,5 & 13 \\
\hline 0,6 & 15 \\
\hline 0,7 & 16 \\
\hline 0,8 & 17 \\
\hline 0,9 & 19 \\
\hline 1,0 & 22 \\
\hline $1,1-1,3$ & 23 \\
\hline 1,4 & 25 \\
\hline $1,5-1,6$ & 27 \\
\hline $1,7-1,8$ & 25 \\
\hline 1,9 & 26 \\
\hline 2,0 & 25 \\
\hline $2,1-2,3$ & 26 \\
\hline 2,4 & 25 \\
\hline $2,5-2,6$ & 26 \\
\hline $2,7-2,8$ & 25 \\
\hline $2,9-3,1$ & 24 \\
\hline 3,2 & 22 \\
\hline $3,3-3,4$ & 21 \\
\hline 3,5 & 20 \\
\hline 3,6 & 19 \\
\hline $3,7-3,9$ & 18 \\
\hline $4,0-4,9$ & 17 \\
\hline & \\
\hline & \\
\hline & \\
\hline & \\
\hline & 26 \\
\hline
\end{tabular}

Pada Tabel 2 merupakan daftar lengkap jumlah benar setiap nilai threshold pada percobaan vefifikasi wajah . Hasil dari percobaan verifikasi wajah juga dapat dilihat pada gambar 15 .

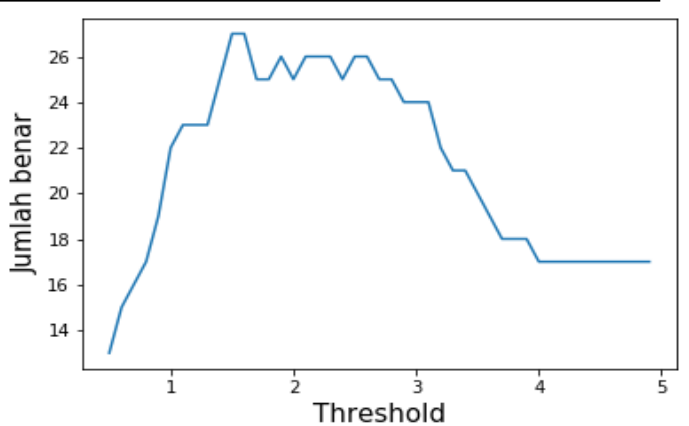

Gambar 15. Grafik jumlah Benar Setiap Nilai Threshold.

Pada gambar 15 bisa dilihat nilai threshold 1,5 dan 1,6 mendapat jumlah benar terbanyak.Terlihat pada grafik gambar 15 jumlah benar terbanyak didapat ketika nilai threshold berada pada nilai 1,5 dan 1,6 denga mendapat jumlah benar sebanyak 27 dari 30 percobaan.

\section{KESIMPULAN DAN SARAN}

\subsection{KESIMPULAN}

Berdasarkan pemaparan hasil penelitian pada bagian IV bisa disimpulkan beberapa hal yaitu:

1. Arsitektur jaringan Siamese berhasil mempelajari fitur wajah pada Dataset VGGv2 menggunakan ResNet-50 sehingga mampu menghasilkan embedding yang baik.

2. Arsitektur jaringan Siamese berhasil dalam mempelajari embedding gambar menggunakan ResNet-50 yang telah dimodifikasi dengan akurasi $92 \%$ pada data testing.

3. Model berhasil mempelajari fitur pada data training dan telah diuji pada data testing dan mendapatkan nilai AUC sebanyak $97 \%$.

\subsection{SARAN}

Pengembangan selanjutnya dapat diterapkan pada CCTV atau menggunakan hardware Rasbery Pi.

\section{REFERENSI}

[1] T. Mulyono, K. Adi, and R Gernowo, "Sistem Pengenalan Wajah Dengan Metode Eigenface Dan Jaringan Syaraf Tiruan (Jst)," Berk. Fis., vol. 15, no. 1, pp. 15-20, 2012.

[2] D. A. A. Kusuma, F. Ardilla, and 
B. S. B. Dewantara, "Verifikasi Citra Wajah Menggunakan Metode Discrete Cosine Transform Untuk Aplikasi Login," Ind. Electron. Semin., vol. 8, no. 5, p. 55, 2011.

[3] B. Huang, "FaceNet: A Unified Embedding for Face Recognition and Clustering," pp. 1-2, 2015.

[4] A. Hermans, L. Beyer, and B. Leibe, "In Defense of the Triplet Loss for Person Re-Identification," 2017.

[5] R. Ranjan, C. D. Castillo, and R. Chellappa, "L 2 -constrained Softmax Loss for Discriminative Face Verification," 2017. 